\title{
Evaluating Mechanical Thrombectomy Techniques Used For The Patients With Ischemic Stroke In Ghaem Hospital Of Mashhad University Of Medical Science
}

Mohammadreza Sobhani ${ }^{1}{ }^{*}$,Humain Baharvahdat ${ }^{2}$, Payam Sasannejad ${ }^{2}$, Kavian Ghandehari ${ }^{2}$,

Hamzeh Dehghanizadeh ${ }^{3}$

${ }^{1}$ Resident of Neurology , M ashhad University of medical sciences, Iran.

${ }^{2}$ Assistant Professor, M ashhad University of medical sciences, Iran.

${ }^{3}$ Resident of Neurosurgery, Mashhad University of medical sciences, Iran.

Introduction: R tpa injection is a routine and common therapeutic approach in treatment of ischemic stroke patients, but it's use has been limited because of contraindications and limited time span. And because of low success in resolution of thrombus in MCA and ICA arteries. The novel and complementary approach is opening main arteries by mean of mechanical thrombectomy.

Methods and material: 27 patients with ischemic stroke underwent mechanical thrombectomy during Jan 2014 to Dec 2016 at Ghaem hospital catheterization lab.

Results: Patients including 17 women and 10 gentlemen underwent thrombectomy. We used for our patients these number of techniques, IA rtPA $=5, I$ A integrilin $=1$, solitaire $=21$, eric $=4$, suction $=13$, balloon and stent $=6$, IA integrilin=1, Solitaire $=21, E R I C=4$, Suction $=13$.

Conclusion: We found that the best technique is unique for each patient, but the best outcome obtained from the combination of the above mentioned techniques.

Key words: Thrombectomy techniques, Ischemic stroke, Evaluation.

DOI: $10.7575 /$ aiac.abcmed.ca1.72

Published Date: February 2017

Peer-review is under responsibility of the 9th Iranian Stroke Congress.

Published by Australian International Academic Centre, Australia

This published work is open access under the CC BY license.

Available online at www.abcmed.aiac.org.au 